\title{
Study on Monitoring Water Area in Irrigation Area by Local Space Self- correlation Index
}

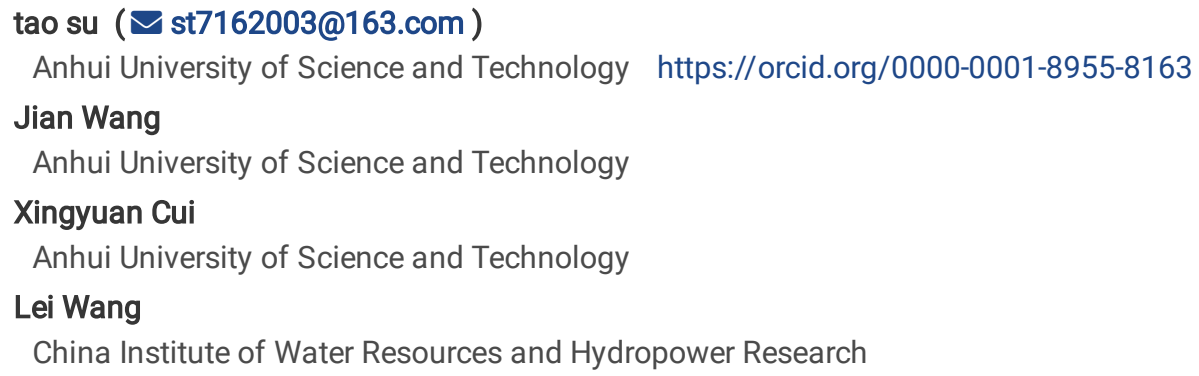

\section{Research Article}

Keywords: remote sensing, hot spot analysis, water index, classification, irrigation area

Posted Date: January 3rd, 2022

DOI: https://doi.org/10.21203/rs.3.rs-1040118/v1

License: (c) (7) This work is licensed under a Creative Commons Attribution 4.0 International License. Read Full License 


\section{Abstract}

Landsat remote sensing image is a widely used data source in water remote sensing. Normalized difference water index (NDWI), modified normalized difference water index (MNDWI) and automated water extraction index (AWEI) are commonly used water extraction classifiers. In the process of their application, because the threshold varies with the location and time of the research object, how to select the threshold with the highest classification accuracy is a time-consuming and challenging task. The purpose of this study was to explore a method that can not only improve the accuracy of water extraction, but also provide a fixed threshold, and can meet the requirements of automatic water extraction. We introduced the local spatial auto correlation statistics and calculate the Getis-Ord Gi* index to have hot spot analysis. Comparative analysis showed that the accuracy of water classification had been greatly improved through hot spot analysis. AWEI $\mathrm{Sh}_{\mathrm{sh}} \mathrm{Classifier}$ had the best classification accuracy under the condition of INVERSE_DISTANCE neighborhood rule and $Z>1.96$, and the accuracy changes least in different time, different location and different vegetation coverage images. Therefore, in the process of regional water extraction, hot spot analysis method was effective, which was helpful to improve the accuracy of water extraction.

\section{Introduction}

According to FAO (FAO. 2018), the global population will reach 9.7 billion by 2050 and 108 billion by 2080 , and food demand is expected to increase significantly, driven by demographic factors. About one third of the world's farmland is moderately or highly degraded, especially in dry land areas. To increase agricultural production, Irrigation is one of the effective measures. It can provide artificial water and better growth conditions for crops, thus the crops can obtain higher average crop yields to meet global food needs, it is the basic tool for meeting world food security, but the heavy use of available water resources has led to severe depletion of rivers and groundwater. With the development of social economy, the contradiction between agricultural water and industrial city water is increasing, and the importance of irrigation in land management and its impact on regional and global climate are gradually recognized by people, which also has attracted the attention of the scientific community (Zohaib et al. 2019; Lawston et al. 2020; Abolafia-Rosenzweig et al. 2019). The rational development, efficient utilization and optimal allocation of water resources are becoming more and more important.

Remote sensing technology provides a new direction for irrigation area monitoring and can better support water resources and agricultural development (Gao et al. 2018). Irrigation can change surface energy balance and hydrological cycle (Douglas et al. 2009; Ryan et al. 2017; Pielke et al. 2011) by changing soil water content, evapotranspiration and surface temperature. Therefore, remote sensing monitoring of irrigation area can be classified according to the difference of surface parameters by inversion, so as to obtain the spatial distribution of irrigation area. Surface parameters usually include soil water content, soil roughness, surface temperature, evapotranspiration, etc. Studies have shown that the irrigation area can be monitored through these surface parameters (Zohaib et al. 2019; Gao et al. 2018). Zohaib et al. (2019) used irrigation-dependent variables such as soil moisture, surface temperature and surface albedo to obtain the spatial distribution of irrigation, and also verified it in three irrigation areas. The results show that the 3-parameter test map has a reasonable consistency with the reference irrigation area. Tuinenburg et al. (2019) found that increasing soil water content parameters during ERAl assimilation can reasonably obtain irrigation water demand. Peña-Arancibia et al. (2014) plot the irrigation area with region effective radiation, evapotranspiration and precipitation parameters as training data set, and the kappa coefficient can reach $96 \%$.

The results show that the spectral indices such as normalized difference vegetation index (NDVI), normalized difference water index (NDWI) and green vegetation index (GVI) can effectively obtain the mapping of irrigation area (Gao et al. 2018; Kamthonkiat et al. 2005; Xiao et al. 2005). Xiang et al. (2019) take Northeast China as the research area, draw the spatial distribution of irrigation area by using land surface water index (LSWI) combined with the difference characteristics of LSWI between irrigation area in arid areas and forest irrigation area. The research shows that this method is a promising mapping tool for irrigation area. Bousbih et al. (2018) take the semi-arid region in central Tunisia as the research area, by analyzing the characteristics of soil moisture and NDVI products over time, the spatial distribution of irrigation and rain-fed areas in the study area was obtained, the accuracy rate was $77 \%$. Jin et al. (2016) used HJ-1a satellite data to calculate NDVI, created time series of wheat growth period, used support vector machine (SVW) algorithm, established classification model, and obtain spatial distribution of rain-fed and irrigation areas, the overall accuracy was $96 \%$. Sharma et al. (2018) obtained parameters such as NDVI, NDWI and enhanced vegetation index (EVI) through Landsat data, then combined with ground observation data and used vector machine model to classify irrigation and non-irrigated areas and gained the high classification accuracy (Kappa coefficient>0.9). Chance et al. (2018) used Landsat5-8 data to obtain the NDWI and applied binary thresholds to distinguish between irrigated and non-irrigated plots. We can see that NDWI and LSWI spectral indices are often used to monitor irrigation conditions (Xiang et al. 2019; Sharma et al. 2018; Chance et al. 2018).

After obtaining surface parameters or vegetation index based on remote sensing technology, the spatial distribution of effective irrigation area of cultivated land is drawn by supervised classification methods such as the maximum likelihood method, random forest model and decision tree, but the classification accuracy of such methods is closely related to the quantity and quality of samples. There are usually two ways to obtain samples: one is visual interpretation on remote sensing images. To use this method the researchers must have strong logical judgment 
and image interpretation ability, but the subjective consciousness of researchers is often mixed, so the quality of samples obtained by visual interpretation is different. The other is to determine samples through field investigation, which is expensive and time-consuming to collect samples. The irrigation area obtained by such methods may not be universal and lack of repeatability, and the differences in the location or number of samples may affect the classification results. Therefore, it is of practical significance to develop a more objective, convenient and universal method for monitoring irrigation area.

Spatial autocorrelation local index (LISA) reflects the "local" related properties of each spatial object attribute, focuses on identifying local changes in spatial dependent patterns, and helps to discover whether there is spatial autocorrelation in local space (Anselin et al. 1995; Getis et al. 1992). Common spatial autocorrelation indexes include Moran's I, Getis-Ord Gi* and local Geary's C (Anselin et al. 1995; Getis et al. 1992; Ord et al. 1995, 2001). Since LISA has the potential to identify hot spots and cold spots, it can be used to identify the homogeneous and heterogeneous types of surface patches to assist in decision analysis. Kowe et al. (2020) analyzed the time variability of vegetation patches in Weharare, Zimbabwe by using landscape index and LISA index based on Landsat series data for many years, and further demonstrated the application of LISA index in hot spots and zero identification. Dalposso et al. (2013) calculated NDVI and GVI by Landsat data, and studied the soybean spectral characteristics of 36 cities in the west of Parana by using spatial statistics method, so as to understand the farming characteristics of each city and provide important information for soybean yield planning.

Irrigation changes the local soil water content, surface albedo (Xiang et al. 2019; Sharma et al. 2018; Chance et al. 2018) and other surface parameters. The method of "hydrology blackward" was verified to be able to monitor irrigation status (Brocca et al. 2014). However, when using the common water body or soil moisture sensitive spectral index to obtain irrigation conditions in the study area, it is often needed to set a threshold and the difference of threshold value directly affects the accuracy of monitoring. The optimal threshold setting needs to be determined based on the ground test samples or area-of-interest (ROI), and the workload is large which is not conducive to automatic irrigation in the study area. Therefore, this study selects multi-temporal Landsat remote sensing image as the data source, uses the common water spectral sensitivity index, and attempts to use the spatial autocorrelation analysis method to automatically obtain the irrigation situation of Hetao Irrigation Area in Inner Mongolia of China, then further illustrates the objectivity and convenience of spatial autocorrelation analysis method, and provides a new method for monitoring irrigation.

\section{Materials And Methods}

\subsection{Study Area}

Hetao Irrigation Area is located in the west of Inner Mongolia Autonomous Region of China, with Yinshan Mountain in the north, Yellow River in the south, Ulan Buhe Besert in the West and Baotou in the East. It is about $200 \mathrm{~km}$ long from east to west, 40-60 km wide from south to north, located at $106^{\circ} 20 \rrbracket-109^{\circ} 19 \bigotimes \mathrm{E}$ and $40^{\circ} 19 \rrbracket-41^{\circ} 18 \rrbracket \mathrm{N}$. It is one of the three largest irrigation districts in China and the largest free flow irrigation area in Asia. It was selected as the world irrigation project heritage in 2019. The terrain of the irrigation area is flat, with an altitude of $1007-1050 \mathrm{~m}$. The main crops are corn, sunflower and wheat. The total land area of irrigation area is $1.12 \times 10^{6} \mathrm{hm}{ }^{2}$, and the annual Yellow River Diversion volume is about $5 \times 10^{9} \mathrm{~m}^{3}$. It is divided into three irrigation periods every year, namely summer irrigation period, autumn irrigation period and autumn pouring period. The total irrigation area is about $6.67 \times 10^{5} \mathrm{hm}^{2}$. Due to different irrigation periods, the irrigation situation of the same cultivated land is different. According to the remote sensing images of different time phases and the actual situation of cultivated land irrigation, two cultivated land was selected as the research area in Hetao area (as shown in Figure 1).

\subsection{Datasets}

In this study, Landsat8 OLI/TIRS was selected as the remote sensing data of the study area (the whole study area needs 2 scenes to synthesize). According to the difference of irrigation schedule and ground crop coverage, the time periods of 20190421 (no crop cover on cultivated land) and 20200610 (crop cover on cultivated land) were selected to study the applicability of spatial autocorrelation analysis method. The orbit numbers of the remote sensing satellites are 129/31 and 129/32 respectively, with a total of 4 images. The quality of the image products is good. All remote sensing images have to be preprocessed by radiation correction and atmospheric correction before use (Teillet et al. 1997; Schroeder et al. 2006; Young et al. 2017; Kotchenova et al. 2006). Due to the low spatial resolution of Landsat8 remote sensing image, this paper selects sentinel 2A remote sensing data of the same or similar time phase as the comparative test data to verify the cultivated land irrigation situation of the study area obtained by using Landsat8 as the data source. 
Table 1

List of remote sensing data

\begin{tabular}{|llll|}
\hline Date & Sensor & Time of passing territory(GMT) & Agency \\
\hline $2019.04 .21^{1}$ & Landsat8 & $03: 29: 37$ & USGS \\
& & & https://glovis.usgs.gov/ \\
\hline $2019.04 .20^{2}$ & Sentinel-2A & $03: 45: 41$ & ESA \\
& & & https://scihub.copernicus.eu/ \\
$2020.06 .10^{3}$ & Landsat8 & $03: 30: 11$ & USGS \\
& & & https://glovis.usgs.gov/ \\
\hline 2020.06 .10 & Sentinel-2A & $03: 35: 41$ & ESA \\
& & & https://scihub.copernicus.eu/ \\
\hline 1 Abbreviated as $20190421 ;{ }^{2}$ Abbreviated as 20190420; ${ }^{3}$ Abbreviated as 20200610.
\end{tabular}

\subsection{Method Description}

\subsubsection{Water Sensitive Spectrum Index}

The common water spectral indexes including NDWI (McFeeters et al. 1996), MNDWI (Xu et al. 2006; Yao et al. 2019) and two automatic water extraction indexes ( $\mathrm{AWEI}_{\mathrm{nsh}}$ and $\mathrm{AWEI}_{\mathrm{sh}}$ ) (Feyisa et al. 2014; Ji et al. 2009) were selected for the study. The calculation formula can be described as follows:

\begin{tabular}{|c|c|}
\hline$N D W I=\left(\rho_{\text {GREEN }}-\rho_{\text {NIR }}\right) /\left(\rho_{\text {GREEN }}+\rho_{\text {NIR }}\right)$ & (1) \\
\hline MNDWI $=\left(\rho_{\text {GREEN }}-\rho_{\text {SWIR }}\right) /\left(\rho_{\text {GREEN }}+\rho_{\text {SWIR }}\right)$ & (2) \\
\hline $\operatorname{AWEI}_{\mathrm{nsh}}=4 \times\left(\rho_{\mathrm{GREEN}}-\rho_{\mathrm{SWIR} 1}\right)-\left(0.25 \times \rho_{\mathrm{NIR}}+2.75 \times \rho_{\mathrm{SWIR} 1}\right)$ & (3) \\
\hline $\mathrm{AWEI}_{\mathrm{Sh}}=\rho_{\mathrm{BIUE}}+2.5 \times \rho_{\mathrm{GREEN}^{-1}}-5 \times\left(\rho_{\mathrm{NIR}}+\rho_{\mathrm{SWIR} 1}\right)-0.25 \times \rho_{\mathrm{SWIR} 2}$ & (4) \\
\hline
\end{tabular}

\subsubsection{Spatial Autocorrelation Analysis}

Spatial autocorrelation refers to the statistical correlation between some attribute values of geographical objects distributed in different spatial positions. Generally, the closer the distance between the two values, the greater the correlation (Anselin et al. 1995; Getis et al. 1992). Global Moran's I index focuses on the analysis of the overall distribution state of a certain attribute value in spatial data (Anselin et al. 1995; Getis et al. 1992).

The range of Moran's I index is [-1,1], I>0 represents the spatial positive correlation and tends to spatial aggregation; $\mid<0$ represents the spatial negative correlation and tends to spatial dispersion; $\mathrm{I}=0$ indicates that the attribute values tend to spatial random distribution feature.

Local spatial autocorrelation is used to further measure the similarity and correlation between the attribute values of each unit and its adjacent spatial units. The results can visually show the spatial agglomeration and dispersion of geographical elements in the region in the form of graphics, and reveal the structural characteristics of its spatial distribution.

The commonly used Moran's I index includes local Moran's I, local gear's C and Getis-Ord Gi* index. Although both local Moran's I and local gear's $\mathrm{C}$ indices can be used to test the local spatial autocorrelation analysis, they can not distinguish cold spot from hot spot. Getis-Ord Gi* index is a local spatial autocorrelation index based on distance weight matrix, which can detect high-value agglomeration and low-value agglomeration, and can obtain spatial agglomeration distribution of high value or low value elements by using $Z$ score and $P$ value (Getis et al. 1992).

\section{Results}




\subsection{Using Different Classifiers to Obtain the Spatial Distribution of Water Bodies in the Study Area}

Using formulas (1), (2), (3), and (4), the water sensitive spectral indices (moisture classifiers) such as NDWI, MNDWI, AWEI ${ }_{\text {nsh }}$ and $A W E I_{\text {sh }}$ can be calculated to obtain the spatial distribution of water bodies in the study area according to the fixed threshold (greater than zero).

Combined with the synchronous (near synchronous) sentinel 2 (S-2) remote sensing image, the cultivated land irrigation water body, non irrigation water body and areas of interest elsewhere were selected as evaluation samples. The classification accuracy of cultivated land water body and non cultivated land water body were evaluated and analyzed in two periods of no crop coverage (20190421) and crop coverage (20200610) (as shown in Table 2, Table 3). In the selection of cultivated land water body, non-cultivated land water body and other areas of interest, the principle of as comprehensive as possible is followed, and the water bodies with different water quality and vegetation coverage differences are selected to improve the evaluation accuracy.

Table 2

Summary of classification accuracy of cultivated water in different periods

\begin{tabular}{|lllll|}
\hline Classifier & $\mathbf{2 0 1 9 0 4 2 1}$ & \multicolumn{3}{c|}{$\mathbf{2 0 2 0 0 6 1 0}$} \\
\cline { 2 - 5 } & Kappa Coefficient & Overall Accuracy & Kappa Coefficient & Overall Accuracy \\
\hline NDWI & 0.38 & $58.29 \%$ & 0.45 & $72.05 \%$ \\
\hline MNDWI & 0.96 & $97.79 \%$ & 0.91 & $95.50 \%$ \\
\hline AWEI $_{\text {sh }}$ & 0.95 & $97.56 \%$ & 0.88 & $93.97 \%$ \\
\hline AWEI $_{\text {nsh }}$ & 0.65 & $82.17 \%$ & 0.74 & $87.00 \%$ \\
\hline
\end{tabular}

Table 3

Summary of classification accuracy of non-cultivated water in different Periods

\begin{tabular}{|lllll|}
\hline Classifier & $\mathbf{2 0 1 9 0 4 2 1}$ & \multicolumn{3}{c|}{$\mathbf{2 0 2 0 0 6 1 0}$} \\
\cline { 2 - 5 } & Kappa Coefficient & Overall Accuracy & Kappa Coefficient & Overall Accuracy \\
\hline NDWI & 0.47 & $64.67 \%$ & 0.513 & $77.02 \%$ \\
\hline MNDWI & 0.94 & $96.93 \%$ & 0.677 & $84.07 \%$ \\
\hline AWEI $_{\text {sh }}$ & 0.95 & $97.59 \%$ & 0.612 & $83.49 \%$ \\
\hline AWEI $_{n s h}$ & 0.55 & $77.26 \%$ & 0.495 & $75.95 \%$ \\
\hline
\end{tabular}

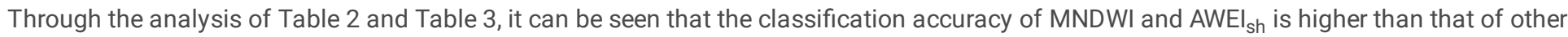
types of classifiers, but the classification accuracy has a certain degree of variation for gaining the water body of different time phases and crop coverage. For cultivated land water bodies in different periods, the classification accuracy of MNDWI classifier is $84.79 \%$ and $88.50 \%$, and that of $\mathrm{AWEI}_{\mathrm{sh}}$ classifier is $87.56 \%$ and $89.97 \%$, respectively; For the non cultivated water in different periods, the classification accuracy of MNDWI classifier was $91.93 \%$ and $84.07 \%$, while that of $\left.A W E\right|_{\text {sh }}$ classifier was $92.59 \%$ and $83.49 \%$, respectively. To sum up, the classification accuracy of water body obtained by the classifier with fixed threshold will be affected by different phases and vegetation coverage, and the change range is large, which is not conducive to the monitoring of water body.

\subsection{Spatial Autocorrelation Analysis}

When using water sensitive spectral index (classifier) to extract regional water, due to the differences of research objects, such as water quality, weather, etc., in order to further improve the classification accuracy, researchers usually adjust the threshold size dynamically (Xu et al. 2006; Feyisa et al. 2014; Ji et al. 2009). For different types of classifiers, the range of threshold adjustment is also quite different. Dynamic threshold is not conducive to quickly obtain the spatial distribution of water body in the study area. In view of this situation, the spatial information processed by different water sensitive spectral indexes (classifiers) is further processed by using spatial autocorrelation analysis method, so as to obtain the spatial concentration distribution of water body, and then the fixed threshold method is used to obtain the spatial distribution of regional water body. The steps are as follows: 1) spatial autocorrelation analysis is performed on the spatial information processed by different water sensitive spectral indexes (classifiers); 2) global Moran index is calculated to judge whether there is aggregation or abnormal value in the study area; 3 ) If there is aggregation or outliers, the local spatial autocorrelation is used to analyze and calculate the Getis-Ord Gi* index to obtain the spatial distribution of hot spots; 4) using Z score and P value to obtain spatial distribution of water body. 
The classification accuracy of water body can be improved by local spatial autocorrelation analysis, but different neighborhood rules need to be selected when calculating Getis-Ord Gi* index identifies hot spots. In this section, three neighborhood rules, such as INVERSE_DISTANCE (ID), INVERSE_DISTANCE_SQUARED (IDS) and FIXED_DISTANCE_BAND (FDB) are selected. Under the original hypothesis of no spatial autocorrelation, if $Z>1.96$, the original hypothesis of no spatial autocorrelation can be rejected at the level of $5 \%$ confidence interval. It can be considered that there is spatial positive autocorrelation, and significant positive value indicates that the units with high observation value tend to gather in space. Therefore, this paper is divided into the following intervals for analysis: 1) $Z>1.68$; 2) $Z>1.96$; 3) $Z>2.58$. By using ArcGIS software, the classification accuracy of irrigation water under different neighborhood rules is studied. According to the actual irrigation situation and the pertinence of the study area, this paper selects two cultivated land as the research object in Hetao Irrigation District (Figure 2). Based on the S-2 remote sensing images of the same period (near synchronous phase), the irrigation water of cultivated land and region of interest for non-water bodies were selected as the evaluation samples. The classification accuracy of cultivated land water was evaluated and analyzed in two periods of no crop coverage (study area 1, 21th, April, 2019) and crop coverage (study area 2, 10th, June, 2020).

(a)

(b)

Figure 2 Typical area location map. (a) is study area 1 ; (b) is study area 2.

\begin{tabular}{|c|c|c|c|c|c|c|c|c|c|}
\hline$\left(a_{1}\right)$ & $\left(b_{1}^{1 \star}\right)$ & $\left(c_{1}^{1 \#}\right)$ & $\left(\mathrm{d}_{1}{ }^{1 \%}\right)$ & $\left(e_{1}^{2 \star}\right)$ & $\left(f_{1}{ }^{2 \#}\right)$ & $\left(g_{1}{ }^{2 \%}\right)$ & $\left(h_{1}^{3 \star}\right)$ & $\left(i_{1}^{3 \#}\right)$ & $\left(\mathrm{j}_{1}{ }^{3 \%}\right)$ \\
\hline$\left(a_{2}\right)$ & $\left(b_{2}{ }^{1 *}\right)$ & $\left(c_{2}{ }^{1 \#}\right)$ & $\left(\mathrm{d}_{2}{ }^{1 \%}\right)$ & $\left(e_{2}^{2 \star}\right)$ & $\left(f_{2}{ }^{2 \#}\right)$ & $\left(g_{2}{ }^{2 \%}\right)$ & $\left(h_{2}^{3 \star}\right)$ & $\left(\mathrm{i}_{2}{ }^{3 \#}\right)$ & $\left(\mathrm{j}_{2}{ }^{3 \%}\right)$ \\
\hline$\left(a_{3}\right)$ & $\left(b_{3}{ }^{1 *}\right)$ & $\left(c_{3}{ }^{1 \#}\right)$ & $\left(d_{3}{ }^{1 \%}\right)$ & $\left(e_{3}^{2 \star}\right)$ & $\left(f_{3}{ }^{2 \#}\right)$ & $\left(g_{3}{ }^{2 \%}\right)$ & $\left(h_{3}^{3 \star}\right)$ & $\left(i_{3}{ }^{3 \#}\right)$ & $\left(\mathrm{j}_{3}{ }^{3 \%}\right)$ \\
\hline$\left(a_{4}\right)$ & $\left(b_{4}^{1 \star}\right)$ & $\left(c_{4}{ }^{1 \#}\right)$ & $\left(\mathrm{d}_{4}{ }^{1 \%}\right)$ & $\left(e_{4}^{2 \star}\right)$ & $\left(f_{4}{ }^{2 \#}\right)$ & $\left(g_{4}{ }^{2 \%}\right)$ & $\left(\mathrm{h}_{4}{ }^{3 \star}\right)$ & $\left(i_{4}^{3 \#}\right)$ & $\left(\mathrm{j}_{4}{ }^{3 \%}\right)$ \\
\hline
\end{tabular}

Figure 3 Comparison of Water Extraction Based on Four Classifiers and Their Different Neighborhood Rule Hotspot Analysis (Study area 1)

Note: figures a1, a2, a3 and a4 show the spatial distribution of water bodies obtained by NDWI, MNDWI, AWEI sh and AWEI nsh $_{\text {classifiers }}$ under fixed threshold conditions respectively; The subscripts 1, 2, 3 and 4 of the the figure number respectively represent the spatial data processed by NDWI, MNDWI, AWEI ${ }_{\text {sh }}$ and $\mathrm{AWEI}_{\text {nsh }}$ classifiers for correlation analysis; The superscripts 1, 2 and 3 of the figure number represent three conditions: z>1.65, z>1.96 and z>2.58; The figure number with *, \# and\% represent ID, IDS and FDB rules respectively.

\begin{tabular}{|c|c|c|c|c|c|c|c|c|c|}
\hline$\left(a_{1}\right)$ & $\left(b_{1}{ }^{1 \star}\right)$ & $\left(c_{1}{ }^{1 \#}\right)$ & $\left(\mathrm{d}_{1}{ }^{1 \%}\right)$ & $\left(e_{1}^{2 \star}\right)$ & $\left(f_{1}^{2 \#}\right)$ & $\left(g_{1}{ }^{2 \%}\right)$ & $\left(\mathrm{h}_{1}{ }^{3 \star}\right)$ & $\left(i_{1}^{3 \#}\right)$ & $\left(\mathrm{j}_{1}{ }^{3 \%}\right)$ \\
\hline$\left(a_{2}\right)$ & $\left(b_{2}{ }^{1 \star}\right)$ & $\left(c_{2}{ }^{1 \#}\right)$ & $\left(d_{2}{ }^{1 \%}\right)$ & $\left(e_{2}^{2 \star}\right)$ & $\left(f_{2}{ }^{2 \#}\right)$ & $\left(\mathrm{g}_{2}{ }^{2 \%}\right)$ & $\left(\mathrm{h}_{2}{ }^{3 \star}\right)$ & $\left(\mathrm{i}_{2}^{3 \#}\right)$ & $\left(\mathrm{j}_{2}{ }^{3 \%}\right)$ \\
\hline$\left(a_{3}\right)$ & $\left(b_{3}{ }^{1 \star}\right)$ & $\left(c_{3}{ }^{1 \#}\right)$ & $\left(d_{3}{ }^{1 \%}\right)$ & $\left(e_{3}^{2 \star}\right)$ & $\left(f_{3}{ }^{2 \#}\right)$ & $\left(g_{3}{ }^{2 \%}\right)$ & $\left(h_{3}{ }^{3 \star}\right)$ & $\left(i_{3}{ }^{3 \#}\right)$ & $\left(\mathrm{j}_{3}{ }^{3 \%}\right)$ \\
\hline$\left(a_{4}\right)$ & $\left(b_{4}^{1 *}\right)$ & $\left(c_{4}{ }^{1 \#}\right)$ & $\left(\mathrm{d}_{4}{ }^{1 \%}\right)$ & $\left(e_{4}^{2 *}\right)$ & $\left(f_{4}{ }^{2 \#}\right)$ & $\left(g_{4}{ }^{2 \%}\right)$ & $\left(\mathrm{h}_{4}{ }^{3 \star}\right)$ & $\left(i_{4}^{3 \#}\right)$ & $\left(\mathrm{j}_{4}{ }^{3 \%}\right)$ \\
\hline
\end{tabular}

Figure 4 Comparison of Water Extraction Based on Four Classifiers and Their Different Neighborhood Rule Hotspot Analysis

(Study area 2)

\section{Note}

figures a1, a2, a3 and a4 respectively show the spatial distribution of water body obtained by NDWI, MNDWI, AWEI sh $_{\text {and }}$ AWEI ${ }_{n s h}$ classifiers under fixed threshold; The subscripts 1, 2, 3 and 4 of the figure number respectively represent the spatial data processed by NDWI, MNDWI, $\mathrm{AWEI}_{\mathrm{sh}}$ and $\mathrm{AWEI}_{\mathrm{nsh}}$ classifiers for correlation analysis; The superscripts 1, 2 and 3 of the figure number represent three conditions: $z>1.65$, z>1.96 and z>2.58 respectively; The figure number marked with *, \# and\% represent ID, IDS and FDB rules .

As shown in Figure 3 and 4, there are some differences between the water spatial distribution obtained by the four water classifiers and the visual interpretation results of remote sensing images, which indicates that only using the fixed threshold method ( $>0$ ) can not meet the requirements of water monitoring accuracy. On the basis of obtaining the spatial distribution of water body by water body classifier, by using different neighborhood rules and Z value division, the spatial aggregation distribution of water body in the study area has certain changes, which tends to the visual interpretation of the image. For crop-free study area 1, four kinds of water body classifier with fixed threshold method 
$(>0)$ were used to obtain water body distribution, the accuracy is $61.2 \%$ (NDVI), 84.08\% (MNDWI), 83.24\% (AWEI sh and $34.35 \%(\mathrm{AWEI}$ nsh), respectively (see Table 4), the water classifiers with the highest accuracy are MNDWI and $\mathrm{AWEI}_{\mathrm{sh}}$, which is consistent with the Feyisa research results (Feyisa et al. 2014). Through hot spot analysis, the accuracy has been greatly improved, especially the accuracy of AWEI $_{\text {nsh }}$ water classifier, which has been improved from 34.35-86.66\%, with the improvement of $52.31 \%$; For the study area with crop cover, most of the selected samples are pixels at the edge of cultivated land water body, so the water precision will generally decrease, which is also in line with the research results of Feyisa (Feyisa et al. 2014). The accuracy of water distribution for four water classifiers with fixed threshold method (>0) was 66.14\% (NDVI), 71.04\% (MNDWI), 72.62\% ( $\mathrm{AWEI}_{\text {sh }}$ ) and 68.32\% (AWEI ${ }_{\text {nsh }}$ ). The water classifiers with the highest classification accuracy were also $\mathrm{MNDWI}$ and $\mathrm{AWEI}_{\text {sh. }}$. Through hot spot analysis, the classification accuracy has also been greatly improved. Therefore, the method of hot spot analysis can obviously improve the classification accuracy of water body.

Because the hot spot analysis method includes different neighborhood rules and different value ranges of $Z$ value, the results of different processing methods have certain differences (as shown in Table 4). It can be seen from Table 4 that the classification accuracy of AWEI sh $_{\text {and }}$ $\mathrm{AWEI}_{\text {nsh }}$ classifiers in study area 1 without crop cover is higher than the highest accuracy of fixed threshold under the condition of different neighborhood rules and different value intervals of $Z$ value, and the values are more concentrated; Under the FDB neighborhood rule, the classification accuracy of MNDWI is higher than that of fixed threshold; Under the condition of different neighborhood rules and different value ranges of $Z$ value, the accuracy of NDWI is general and the value is more dispersed, but its accuracy is higher than the fixed threshold of NDWI. For study area 2 with crop coverage, the classification accuracy of NDWI, MNDWI, AWEI sh $_{\text {and }} \mathrm{AWEI}_{\text {nsh }}$ is higher than the highest accuracy of fixed threshold under FDB neighborhood rules. In hot spot analysis, there are several cases that the classification accuracy is less than that of the fixed threshold of the corresponding classifier, which is concentrated in the case of ID and IDS neighborhood rules and Z > 2.58 , and the worst is 37.10 .

In the case of no vegetation cover and vegetation cover, as well as the original assumption that no spatial autocorrelation should be rejected at the level of reasonable confidence interval, through comparative analysis of the data in Table 4, when ID neighborhood rule and Z > 1.96 are adopted, the accuracy of regional water extraction of $\mathrm{AWEI}_{\text {sh }}$ classifier is better in hot spot analysis. If there is no vegetation cover, the classification accuracy of water body is $86.69 \%$, and that of water body with vegetation cover is $74.92 \%$, which is superior to other neighborhood rules and $\mathrm{Z}$ combination, and is also larger than that of fixed threshold.

Table 4

Evaluation of water extraction accuracy in two study areas

\begin{tabular}{|c|c|c|c|c|c|c|c|c|c|c|c|}
\hline \multirow{4}{*}{$\begin{array}{l}\text { experimental } \\
\text { field }\end{array}$} & \multirow[t]{4}{*}{ classifier } & \multirow{4}{*}{$\begin{array}{l}\text { Overall } \\
\text { Accuracyt }\end{array}$} & \multicolumn{9}{|c|}{ Hot spot analysis } \\
\hline & & & \multirow{2}{*}{\multicolumn{3}{|c|}{$\begin{array}{l}\text { INVERSE_DISTANCE } \\
\text { (ID) }\end{array}$}} & \multirow{2}{*}{\multicolumn{3}{|c|}{$\begin{array}{l}\text { INVERSE_DISTANCE_SQUARED } \\
\text { (IDS) }\end{array}$}} & \multirow{2}{*}{\multicolumn{3}{|c|}{$\begin{array}{l}\text { FIXED_DISTANCE_BAND } \\
\text { (FDB) }\end{array}$}} \\
\hline & & & & & & & & & & & \\
\hline & & & $Z>1.65$ & $Z>1.96$ & $Z>2.58$ & $Z>1.65$ & $Z>1.96$ & $Z>2.58$ & $Z>1.65$ & $Z>1.96$ & $Z>2.58$ \\
\hline \multirow[t]{4}{*}{1} & NDWI & $61.28 \%$ & $82.96 \%$ & $80.75 \%$ & $73.21 \%$ & $81.04 \%$ & $78.47 \%$ & $70.71 \%$ & $85.98 \%$ & $86.10 \%$ & $84.80 \%$ \\
\hline & MNDWI & $84.08 \%$ & $86.19 \%$ & $86.23 \%$ & $83.57 \%$ & $86.24 \%$ & $85.77 \%$ & $80.07 \%$ & $86.20 \%$ & $86.35 \%$ & $86.49 \%$ \\
\hline & $\mathrm{AWEI}_{\text {sh }}$ & $83.24 \%$ & $86.58 \%$ & $86.69 \%$ & $86.26 \%$ & $86.67 \%$ & $86.38 \%$ & $84.59 \%$ & $85.97 \%$ & $86.04 \%$ & $86.25 \%$ \\
\hline & $\mathrm{AWEI}_{\mathrm{nsh}}$ & $34.35 \%$ & $86.57 \%$ & $86.66 \%$ & $86.24 \%$ & $86.66 \%$ & $86.37 \%$ & $86.12 \%$ & $85.90 \%$ & $86.04 \%$ & $86.26 \%$ \\
\hline \multirow[t]{4}{*}{2} & NDWI & $66.14 \%$ & $75.69 \%$ & $74.43 \%$ & $65.66 \%$ & $74.96 \%$ & $71.32 \%$ & $61.48 \%$ & $74.60 \%$ & $74.72 \%$ & $75.35 \%$ \\
\hline & MNDWI & $71.04 \%$ & $72.78 \%$ & $71.83 \%$ & $64.71 \%$ & $72.31 \%$ & $68.57 \%$ & $60.59 \%$ & $74.35 \%$ & $74.76 \%$ & $75.31 \%$ \\
\hline & $\mathrm{AWEI}_{\mathrm{sh}}$ & $72.62 \%$ & $75.54 \%$ & $74.92 \%$ & $63.78 \%$ & $75.38 \%$ & $72.61 \%$ & $51.51 \%$ & $73.57 \%$ & $74.05 \%$ & $74.72 \%$ \\
\hline & $\mathrm{AWEI}_{\mathrm{nsh}}$ & $68.32 \%$ & $75.46 \%$ & $72.78 \%$ & $60.59 \%$ & $73.00 \%$ & $69.81 \%$ & $37.10 \%$ & $73.66 \%$ & $74.01 \%$ & $74.88 \%$ \\
\hline
\end{tabular}

\subsection{Monitoring of Irrigation Water Area in the Study Area}

According to the analysis results of Section 3.2, this section uses ArcGIS software to have hot spots analysis of irrigation water in different periods of the study area by using four water classifiers under the condition of ID neighborhood rule and $Z>1.96$. The classification accuracy is shown in Table 5 and Table 6. 
Table 5

Summary of Classification Precision of Hot Spot of Cultivated Water in Different Periods

\begin{tabular}{|lllll|}
\hline Classifier & $\mathbf{2 0 1 9 0 4 2 1}$ & \multicolumn{3}{c}{$\mathbf{2 0 2 0 0 6 1 0}$} \\
\cline { 2 - 5 } & Kappa Coefficient & Overall Accuracy & Kappa Coefficient & Overall Accuracy \\
\hline NDWI & 0.76 & $88.20 \%$ & 0.82 & $90.84 \%$ \\
\hline MNDWI & 0.74 & $87.05 \%$ & 0.83 & $91.31 \%$ \\
AWEI $_{\text {sh }}$ & 0.90 & $95.02 \%$ & 0.91 & $95.40 \%$ \\
\hline AWEI $_{\text {nsh }}$ & 0.85 & $92.49 \%$ & 0.89 & $94.31 \%$ \\
\hline
\end{tabular}

Table 6

Summary of classification accuracy of non-cultivated water hot spots in different periods

\begin{tabular}{|c|c|c|c|c|}
\hline \multirow[t]{2}{*}{ Classifier } & \multicolumn{2}{|l|}{20190421} & \multicolumn{2}{|l|}{20200610} \\
\hline & Kappa Coefficient & Overall Accuracy & Kappa Coefficient & Overall Accuracy \\
\hline NDWI & 0.79 & $89.36 \%$ & 0.60 & $82.84 \%$ \\
\hline MNDWI & 0.73 & $86.62 \%$ & 0.76 & $91.53 \%$ \\
\hline$A W E I_{s h}$ & 0.90 & $94.85 \%$ & 0.83 & $93.76 \%$ \\
\hline $\mathrm{AWEI}_{\mathrm{nsh}}$ & 0.84 & $92.10 \%$ & 0.79 & $90.75 \%$ \\
\hline \multicolumn{5}{|c|}{ 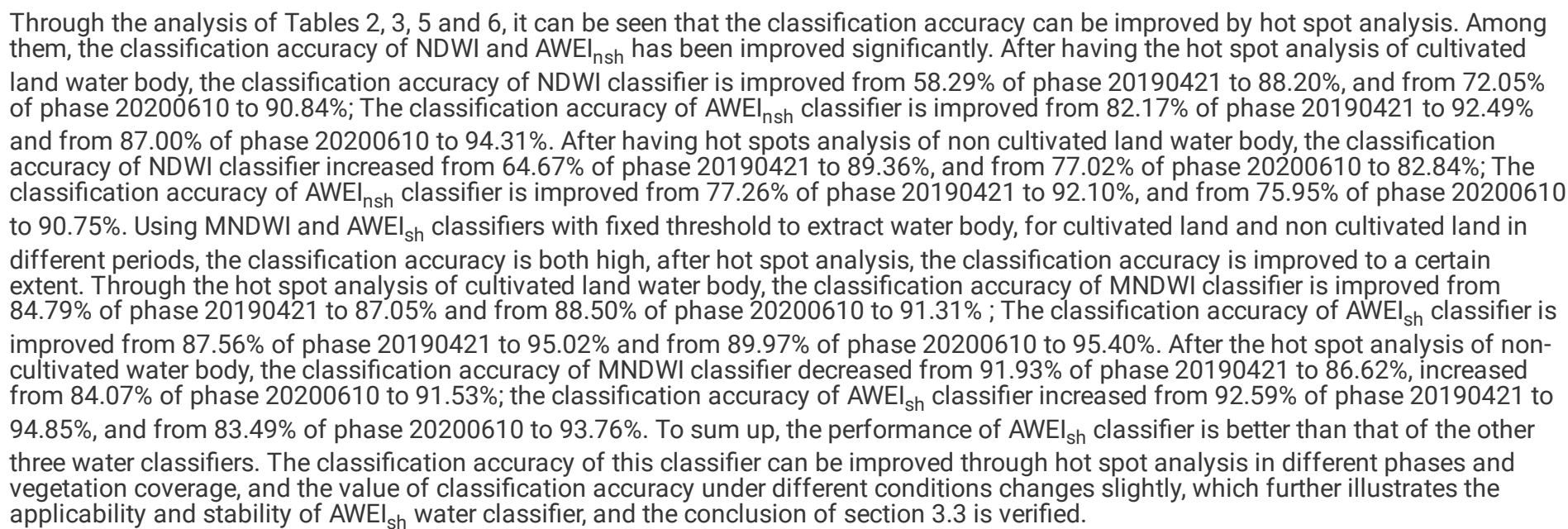 } \\
\hline
\end{tabular}

\section{Discussion}

To achieve the purpose of automatic acquisition of regional water bodies with high accuracy, we selected water indexes such as NDWI, MNDWI, $\mathrm{AWEI}_{\text {sh }}$ and $\mathrm{AWEI}_{\mathrm{nsh}}$ to compare and analyze the water extraction accuracy in the study area by using fixed threshold and hot spot analysis methods. A large number of water extraction experiments were carried out under different time phases and vegetation coverage conditions, which verified that hot spot analysis could improve the accuracy of water extraction, and had good applicability and stability.

In the research process of regional water body extraction method, the method of using water index to extract surface water body is more commonly used. McFeeters uses the band2 and band4 of Landsat TM, introduces NDWI to extract water, and proposes that the threshold value of water extraction is 0 , greater than 0 is water body, and less than 0 is non water body (McFeeters et al. 1996). Rogers and Kearney establish another type of NDWI using band3 and band5 of Landsat TM (Rogers et al. 2004). However, Xu found that the NDWI fixed threshold method could not accurately extract water, so the NDWI was improved and MNDWI was established by using band2 and band5 of Landsat TM (Xu et al. 2006). Nowadays, MNDWI has become one of the most widely used water indexes in surface water extraction, land use and ecological research (Sharma et al. 2018; Chance et al. 2018; Helman et al. 2020; Pickens et al. 2020; Eid et al. 2020). Considering the influence of Urban Surface Shadow and low reflectivity area on water extraction accuracy and the possibility of automatic water extraction, Feyisa proposed $\mathrm{AWEI}_{\mathrm{sh}}$ and $\mathrm{AWEI} \mathrm{nsh}_{\text {water index (Feyisa et al. 2014). To sum up, in this study, we selected NDWI, MNDWI, AWEI }}$, and AWEI ${ }_{\text {nsh }}$ Water indexes for water extraction and comparison test. 
Unfortunately, different spatial distributions of water bodies may be obtained when using these four water indices to extract surface water (Jiang et al. 2014; Kelly et al. 2018). Ji et al. (2009) think that there are two main problems in using water index to extract surface water. First, the results are inconsistent and unreliable when different water body indexes are used to extract surface water; Second, the threshold value for dividing surface water body is unstable and varies with different locations and scenes. Therefore, researchers have been committed to improving the accuracy and threshold of water extraction (Feyisa et al. 2014; Worden et al. 2020; Kelly et al. 2018). The selection of test area is one of the important links to evaluate whether the hot spot analysis method has wide applicability and stability. In this study, a large area and two small areas are selected as the research objects. The large area is the whole Hetao irrigation area, and the small areas are the cultivated land with different vegetation coverage and periods. We strive to create experimental areas with different scenarios to objectively evaluate the applicability and stability of hot spot analysis method.

The fixed threshold method (greater than zero) was used to extract water from Hetao Irrigation Area in different periods by using four water indexes, and the spatial distribution of water body was different. For different land types at the same time and the same land type at different times, the accuracy of water extraction using the same water index was also different (as shown in Figure 5). It can be seen from Figure 5 that the water extraction accuracy of NDWI is the least ideal compared with water extraction accuracy of other indexes, and its accuracy changes most violently, with the lowest value of $58.29 \%$ and the highest of $77.02 \%$. The water extraction accuracy of NDWI is generally low, which is consistent with the research conclusion of Xu et al. (2006); The water extraction accuracy of AWEI sh seems to have a certain change rule. The water extraction accuracy of cultivated land is higher than that of non cultivated land. The water extraction accuracy of cultivated land with crop cover is $87.00 \%$ and it is significantly higher than that of non cultivated land (75.95\%) in the same period. The water extraction accuracy of cultivated land without crop cover is $82.17 \%$ and it is higher than that of non cultivated land $(77.26 \%)$ in the same period; The water extraction accuracy of AWEI sh index and MNDWI index is close to the same, and the water extraction accuracy of $\mathrm{AWEI}_{\mathrm{sh}}$ index is slightly higher than that of $\mathrm{MNDWI}$, indicating that $\mathrm{AWEI}_{\text {sh }}$ index can inhibit the influence of vegetation coverage and low reflection area on water extraction accuracy.

The extraction accuracy of water body by fixed threshold method is often not ideal by using water index such as NDWI, MNDWI,AWEI and $\mathrm{AWEI}_{\mathrm{nsh}}$, and further adjustment of the threshold is needed to achieve the ideal accuracy. However, different regions and different scenes have different thresholds, which makes it difficult to select the threshold when extracting water. The unstable threshold may make the classification more time-consuming and subjective, and may ultimately affect the accuracy of water extraction. We use hot spot analysis method to extract water body, which can not only further improve the accuracy of water extraction, but also has objectivity, which makes the use of this method more simple and convenient.

In our study, two regions with crop coverage and no crop coverage were selected as the research objects. Using the hot spot analysis method to extract water bodies, it was found that the water extraction accuracy of various water indexes (under $Z>1.96$ condition) was

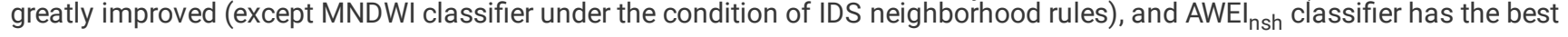
classification accuracy under the ID neighborhood rule and the $Z>1.96$ condition. The difference of $Z$ value selection also affects the accuracy of water extraction. In general, too large selection of $Z$ value $(Z>2.58)$ may reduce the accuracy of water extraction, but there are also exceptions, for example, in the second study area, for $\mathrm{AWEI}_{\text {nsh }}$ classifier, the accuracy of water extraction is $69.81 \%$ under the condition of IDS neighborhood rule and $Z>1.96$, while the extraction accuracy drops sharply to $37.10 \%$ when $Z>2.58$, but is opposite for water extraction accuracy under FDB neighborhood rules, the extraction accuracy reaches $74.88 \%$, which is higher than $74.01 \%$ when $Z>1.96$. In general, we can see that the water extracted accuracy of four water indexes by using hot spot analysis method is greatly improved under the conditions of three neighborhood rules and Z>1.96 (except MNDWI classifier under the condition of IDS neighborhood rules).

Although the hot spot analysis method is tested in a wide range of environmental conditions and different water body types, we did not consider the sun angle, atmospheric factors and water characteristics when selecting the test site, which may affect the extraction of soil water body information by hot spot analysis method. Therefore, when evaluating the accuracy of water extraction by hot spot analysis method, the influence of these factors on the extraction accuracy may need to be considered, and more test points may be included to comprehensively evaluate the hot spot analysis method. Hot spot analysis method is based on Landsat8 data for water extraction test, and may need to be re-evaluated when using other data sources.

\section{Conclusions}

The main purpose of this study is to solve the problem of classifier threshold setting in water monitoring by using hot spot analysis method. Generally, in order to improve the accuracy of water extraction, the optimal threshold of water classifier is changed, which is not conducive to automatic extraction of water. Using Landsat8 OLI remote sensing data, the conventional water index $\mathrm{NDWI} \mathrm{MNDWI} \mathrm{AWEI}$ sh ${ }_{\text {and }} \mathrm{AWEI} \mathrm{nsh}_{\mathrm{Were}}$ selected to classify the water body in the study area under different time phases and vegetation coverage conditions by using the method of fixed threshold. Then, the precision of interest points of water edge, water body and non water body are compared and analyzed. The results show that $\mathrm{AWEI}_{\mathrm{sh}}$ has the best accuracy of water classification, but the numerical variation of classification accuracy under different conditions is large, which is not conducive to automatic water extraction. Through hot spot analysis, the classification accuracy of the four water classifiers is improved in general under different neighborhood rules and different value intervals of $Z$ values. Through comparative analysis, $\mathrm{AWEI}_{\text {sh }}$ classifier has the best classification accuracy under ID neighborhood rules and Z>1.96 conditions, and its classification accuracy has the smallest variation range in images with different time, different positions and different vegetation cover. Therefore, the hot spot analysis and treatment method is effective for water extraction, which can further improve the classification accuracy and provide an

Page 9/16 


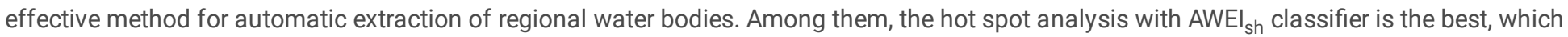
has good applicability and stability.

\section{Declarations}

Author Contributions: Conceptualization, Xingyuan Cui and Lei Wang; Data curation, Jian Wang and Lei Wang; Formal analysis, Lei Wang; Funding acquisition, Xingyuan Cui; Methodology, Tao Su; Software, Jian Wang; Supervision, Lei Wang; Validation, Tao Su and Xingyuan Cui.

Funding: This research was funded by the National Key Research and Development Project of China (Grant no. 2018YFC0407703-1, 2017YFC0403301), Anhui University of Science and Technology Master's and Doctor's Fund Projects (Grant no. ZY030), Natural Science Foundation of the Anhui Higher Education Institutions of China (Grant no. KJ2017A072).

Conflicts of Interest: The authors declare no conflict of interest.

\section{References}

Abolafia-Rosenzweig R, Livneh B, Small E E; Kumar S V (2019) Soil moisture data assimilation to estimate irrigation water use. J Adv Model Earth Sy 11: 3670-3690. doi: 10.1029/2019MS001797

Anselin L (1995) Local indicators of spatial association-LISA. Geogr Anal 27: 93-115. doi: 10.1111/j.1538-4632.1995.tb00338.x

Bousbih S, Zribi M, El Hajj M, Baghdadi N, Lili-Chabaane Z, Gao Q, Fanise P (2018) Soil moisture and irrigation mapping in A semi-arid region, based on the synergetic use of Sentinel-1 and Sentinel-2 data. Remote Sens 10: 1953. doi: 10.3390/rs10121953

Brocca L, Ciabatta L, Massari C, Moramarco T, Hahn S, Hasenauer S, Levizzani V (2014) Soil as a natural rain gauge: Estimating global rainfall from satellite soil moisture data. J Geophys Res Atmospheres 119: 5128-5141. doi: 10.1002/2014JD021489

Chance E W, Cobourn K M, Thomas V A (2018) Trend detection for the extent of irrigated agriculture in Idaho's Snake river plain, $1984-2016$. Remote Sens 10: 145. doi: 10.3390/rs10010145

Dalposso G H, Uribe-Opazo M A, Mercante E, Lamparelli R A (2013) Spatial autocorrelation of NDVI and GVI indices derived from Landsat/TM images for soybean crops in the western of the state of Paraná in 2004/2005 crop season. Engenharia Agrícola 33: 525-537. doi:

$10.1590 /$ S0100-69162013000300009

Douglas E M, Beltrán-Przekurat A, Niyogi D, Pielke Sr R A, Vörösmarty C J (2009) The impact of agricultural intensification and irrigation on land-atmosphere interactions and Indian monsoon precipitation-A mesoscale modeling perspective. Glob Planet Change 67: 117-128. doi: 10.1016/j.gloplacha.2008.12.007

Eid A N M, Olatubara C O, Ewemoje T A, Farouk H, El-Hennawy M T (2020) Coastal wetland vegetation features and digital Change Detection Mapping based on remotely sensed imagery: El-Burullus Lake, Egypt. International Soil and Water Conservation Research 8: 66-79. doi: 10.1016/j.iswcr.2020.01.004

FAO (2018) The Future of Food and Agriculture: Alternative pathways to 2050. Food and Agriculture Organization of the United Nations Publications: Rome, Italy 224.

Feyisa G L, Meilby H, Fensholt R, Proud S R (2014) Automated Water Extraction Index: A new technique for surface water mapping using Landsat imagery. Remote Sens Environ 140: 23-35. doi: 10.1016/j.rse.2014.08.029

Gao Q, Zribi M, Escorihuela M J, Baghdadi N, Segui P Q (2018) Irrigation mapping using Sentinel-1 time series at field scale. Remote Sens 10: 1495. doi: $10.3390 /$ rs10091495

Getis A, Ord J K (1992) The Analysis of Spatial Association by Use of Distance Statistics. Geogr. Anal 24: 189-206. doi: 10.1111/j.15384632.1992.tb00261.x

Helman D, Mussery A (2020) Using Landsat satellites to assess the impact of check dams built across erosive gullies on vegetation rehabilitation. Sci Total Environ 730: 138873. doi: 10.1016/j.scitotenv.2020.138873

Ji L, Zhang L, Wylie B (2009) Analysis of dynamic thresholds for the normalized difference water index. Photogrammetric Eng Rem S 75: 1307-1317. doi: 10.14358/PERS.75.11.1307

Page 10/16 
Jiang H, Feng M, Zhu Y, Lu N, Huang J, Xiao T (2014) An automated method for extracting rivers and lakes from Landsat imagery. Remote Sens 6: 5067-5089. doi: 10.3390/rs6065067

Jin N, Tao B, Ren W, Feng M, Sun R, He L, Yu Q (2016) Mapping irrigated and rainfed wheat areas using multi-temporal satellite data. Remote Sens 8: 207. doi: 10.3390/rs8030207

Kamthonkiat D, Honda K, Turral H, Tripathi N K, Wuwongse V (2005) Discrimination of irrigated and rainfed rice in a tropical agricultural system using SPOT vegetation NDVI and rainfall data. Int J Remote Sens 26: 2527-2547. doi: 10.1080/01431160500104335

Kelly J T, Gontz A M (2018) Using GPS-surveyed intertidal zones to determine the validity of shorelines automatically mapped by Landsat water indices. Int J Appl Earth Obs Geoinf 65: 92-104. do: 10.1016/j.jag.2017.10.007

Kotchenova S Y, Vermote E F, Matarrese R, Klemm Jr F J (2006) Validation of a vector version of the 6S radiative transfer code for atmospheric correction of satellite data. Part I: Path radiance. Appl Optics 45: 6762-6774. doi: 10.1364/A0.45.006762

Kowe P, Mutanga O, Odindi J, Dube T (2020) A quantitative framework for analysing long term spatial clustering and vegetation fragmentation in an urban landscape using multi-temporal landsat data. Int J Appl Earth Obs 88: 102057. doi: 10.1016/j.jag.2020.102057

Lawston P M, Santanello Jr J A, Hanson B, Arsensault K (2020) Impacts of Irrigation on Summertime Temperatures in the Pacific Northwest. Earth Interactions 24: 1-26. doi: 10.1175/El-D-19-0015.1

McFeeters S K (1996) The use of the Normalized Difference Water Index (NDWI) in the delineation of open water features. Int J Remote Sens 17: 1425-1432. doi: 10.1080/01431169608948714

Ord J K, Getis A (2001) Testing for local spatial autocorrelation in the presence of global autocorrelation. J Regional Sci 41: 411-432. doi: $10.1111 / 0022-4146.00224$

Ord J K, Getis A (1995) Local spatial autocorrelation statistics: distributional issues and an application. Geogr Anal 27: 286-306. doi: 10.1111/j.1538-4632.1995.tb00912.x

Peña-Arancibia J L, McVicar T R, Paydar Z, Li L, Guerschman J P, Donohue R J, Chiew F H (2014) Dynamic identification of summer cropping irrigated areas in a large basin experiencing extreme climatic variability. Remote Sens Environ 154: 139-152. doi: 10.1016/j.rse.2014.08.016

Pickens A H, Hansen M C, Hancher M, Stehman S V, Tyukavina A, Potapov P, Sherani Z (2020) Mapping and sampling to characterize global inland water dynamics from 1999 to 2018 with full Landsat time-series. Remote Sens Environ 243: 111792. doi: 10.1016/j.rse.2020.111792

Pielke Sr R A, Pitman A, Niyogi D, Mahmood R, McAlpine C, Hossain F, Reichstein M (2011) Land use/land cover changes and climate: modeling analysis and observational evidence. Wiley Interdisciplinary Reviews: Climate Change 2: 828-850. doi: 10.1002/wcc.144

Rogers A S, Kearney M S (2004) Reducing signature variability in unmixing coastal marsh Thematic Mapper scenes using spectral indices. Int J Remote Sens 25: 2317-2335. doi: 10.1080/01431160310001618103

Ryan E M, Ogle K, Peltier D, Walker A P, De Kauwe M G, Medlyn B E, Harper A B (2017) Gross primary production responses to warming, elevated CO2, and irrigation: Quantifying the drivers of ecosystem physiology in a semiarid grassland. Global Ghange Biol 23: 3092-3106. doi: $10.1111 /$ gcb. 13602

Schroeder T A, Cohen W B, Song C, Canty M J, Yang Z (2006) Radiometric correction of multi-temporal Landsat data for characterization of early successional forest patterns in western Oregon. Remote Sens Environ 103: 16-26. doi: 10.1016/j.rse.2006.03.008

Sharma A K, Hubert-Moy L, Buvaneshwari S, Sekhar M, Ruiz L, Bandyopadhyay S Corgne S (2018) Irrigation history estimation using multitemporal landsat satellite images: Application to an intensive groundwater irrigated agricultural watershed in India. Remote Sens 10 : 893. doi: $10.3390 /$ rs 10060893

Teillet P M, Staenz K, William D J (1997) Effects of spectral, spatial, and radiometric characteristics on remote sensing vegetation indices of forested regions. Remote Sens Environ 61: 139-149. doi: 10.1016/S0034-4257(96)00248-9

Tuinenburg O A, de Vries J P R (2017) Irrigation patterns resemble ERA-Interim Reanalysis soil moisture additions. Geophys Res Lett 44: 10341. doi: $10.1002 / 2017$ GL074884

Worden J, de Beurs K M (2020) Surface water detection in the Caucasus. Int J Appl Earth O B S 91: 102159. doi: 10.1016/j.jag.2020.102159

Page $11 / 16$ 
Xiang K, Ma M, Liu W, Dong J, Zhu X, Yuan W (2019) Mapping Irrigated Areas of Northeast China in Comparison to Natural Vegetation. Remote Sens 11: 825. doi: 10.3390/rs11070825

Xiao X, Boles S, Liu J, Zhuang D, Frolking S, Li C, Moore III B (2005) Mapping paddy rice agriculture in southern China using multi-temporal MODIS images. Remote Sens Environ 95: 480-492. doi: 10.1016/j.rse.2004.12.009

Xu H (2006) Modification of normalised difference water index (NDWI) to enhance open water features in remotely sensed imagery. Int $\mathrm{J}$ Remote Sens 27: 3025-3033. doi: 10.1080/01431160600589179

Yao F, Wang J, Wang C, Crétaux J F (2019) Constructing long-term high-frequency time series of global lake and reservoir areas using Landsat imagery. Remote Sens Environ 232: 111210. doi: 10.1016/j.rse.2019.111210

Young N E, Anderson R S, Chignell S M, Vorster A G, Lawrence R, Evangelista P H (2017) A survival guide to Landsat preprocessing. Ecology 98: 920-932. doi: 10.1002/ecy.1730

Zohaib M, Kim H, Choi M (2019) Detecting global irrigated areas by using satellite and reanalysis products. Sci Total Environ 677 : $679-691$. doi: 10.1016/j.scitotenv.2019.04.365

\section{Figures}

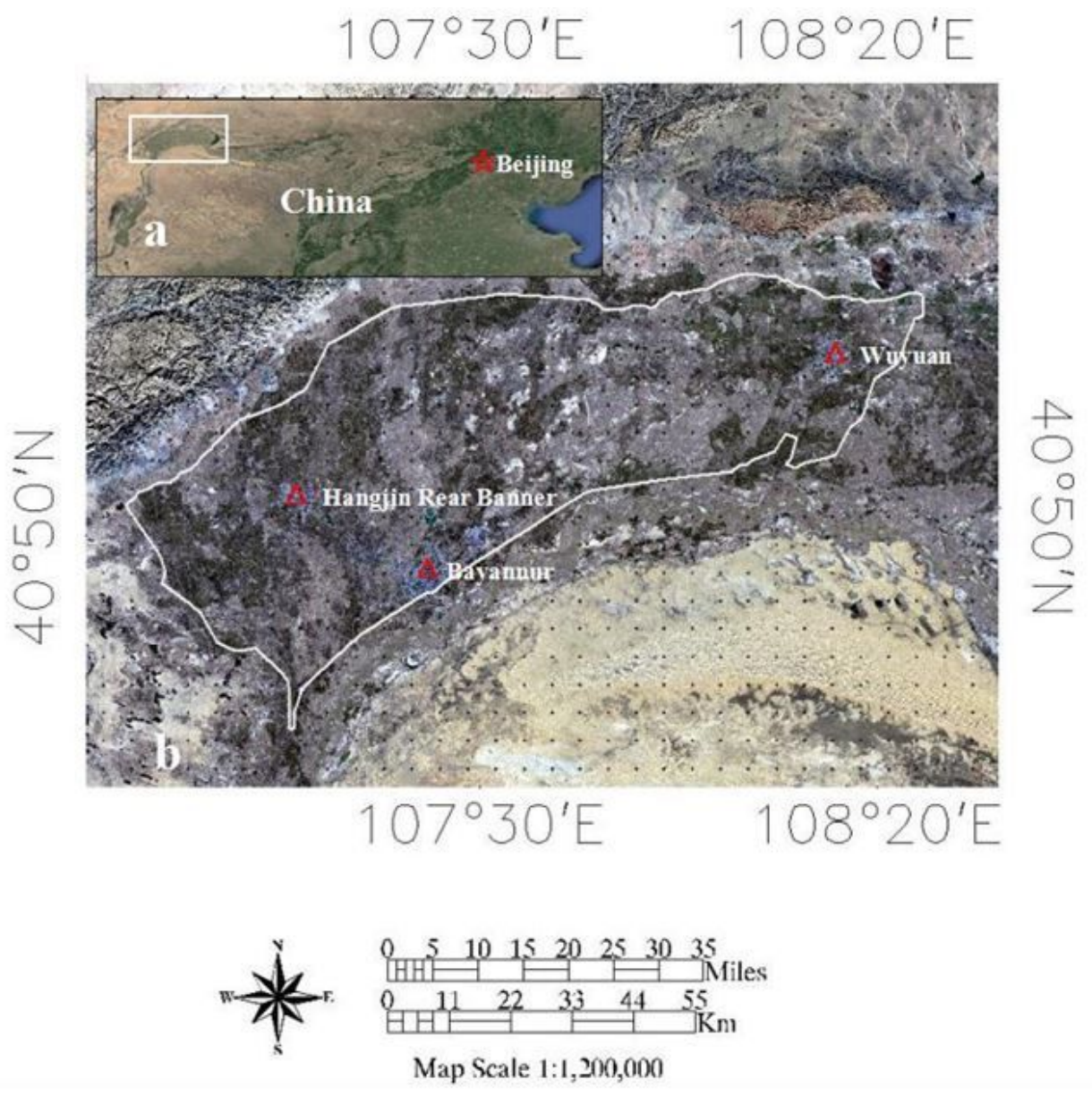

\section{Figure 1}

(a) a is a map of the location of the study area in China; (b) b map is a remote sensing image of the study area based on the true color synthesis of Landsat 8 image (Band 4, band 3, band 2 band synthesis). 


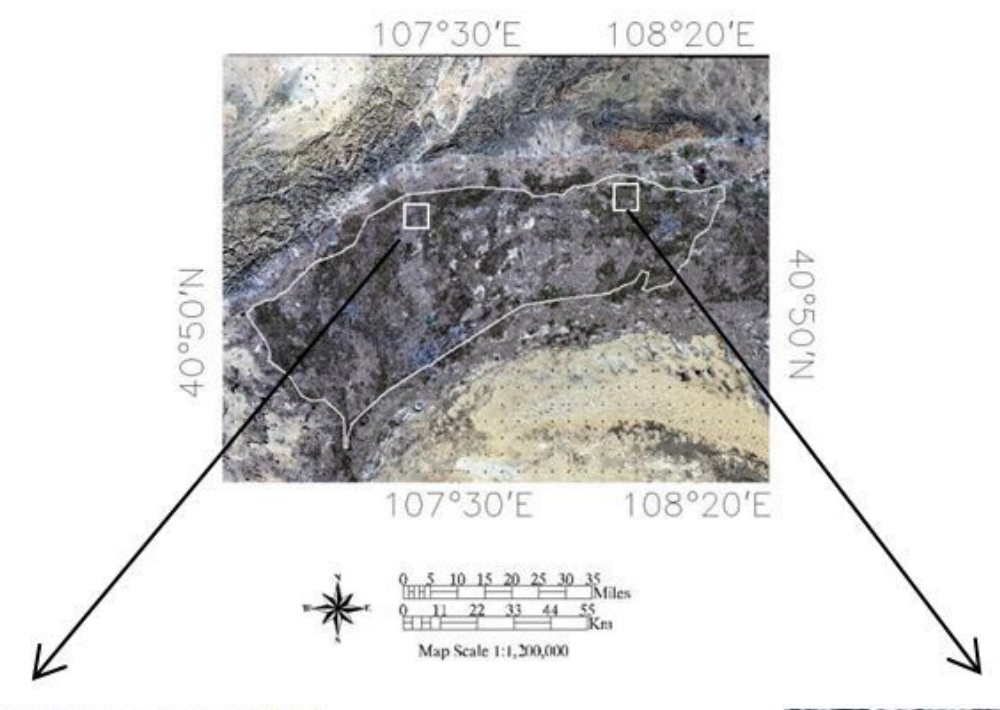

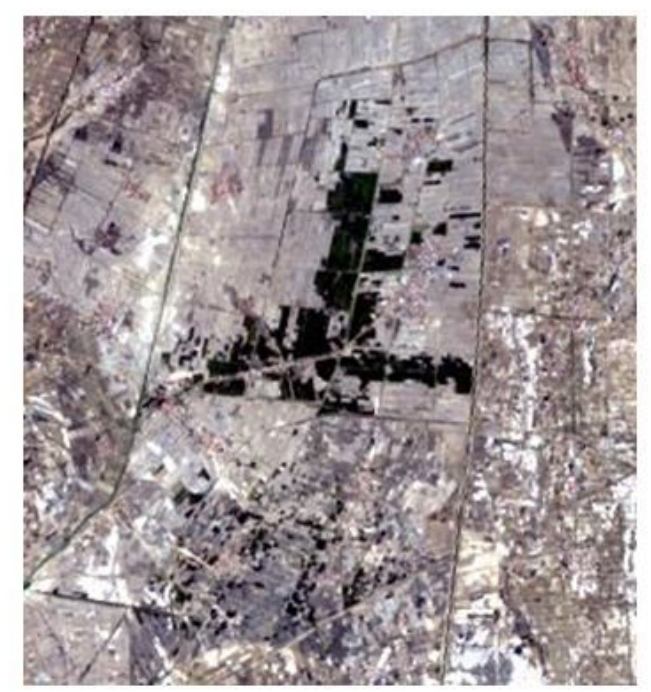

(a)

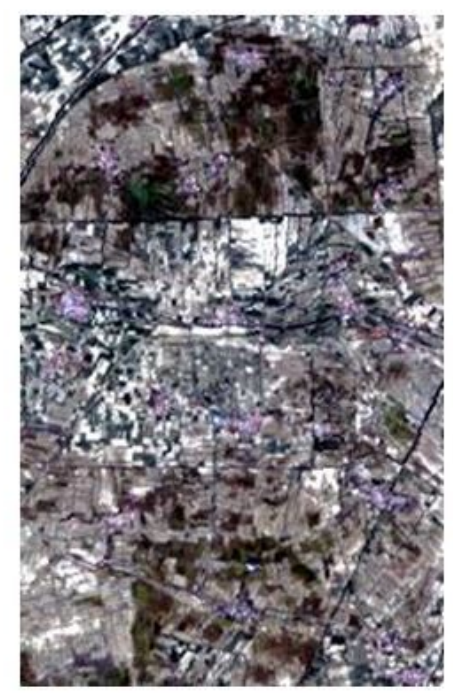

(b)

\section{Figure 2}

(a) a is a map of the location of the study area in China; (b) b map is a remote sensing image of the study area based on the true color synthesis of Landsat 8 image (Band 4, band 3, band 2 band synthesis). 


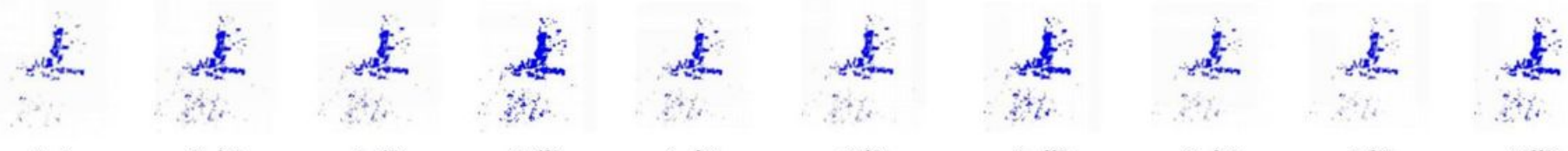

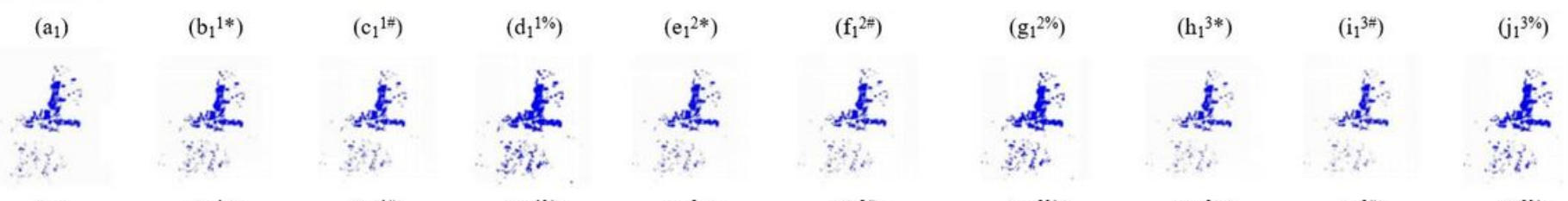

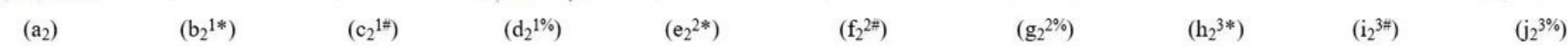

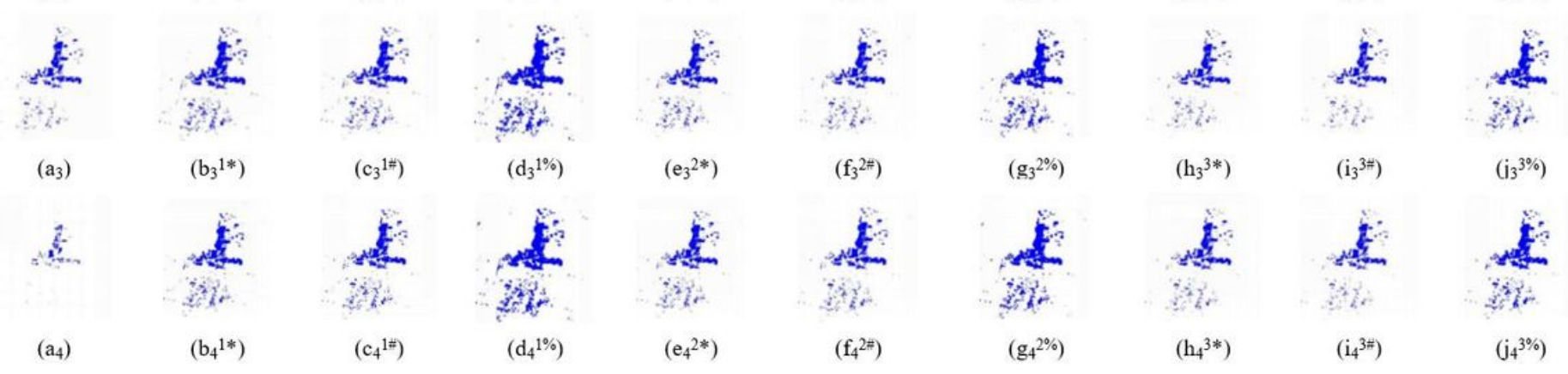

Legend

$\square$ Water
$\square$ Non-water
$\square$ N

Figure 3

Comparison of Water Extraction Based on Four Classifiers and Their Different Neighborhood Rule Hotspot Analysis (Study area 1) 
$2-\frac{3}{4}$

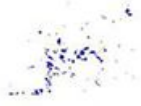

$\left(a_{1}\right)$

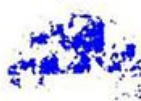

$\therefore$
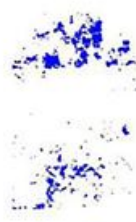

$\left(b_{1}{ }^{1 *}\right)$

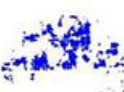

tain
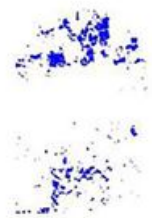

$\left(c_{1}{ }^{1 \#}\right)$

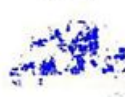

$\therefore$ a
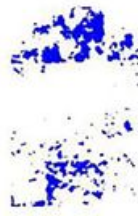

$\left(\mathrm{d}_{1} 1 \%\right)$

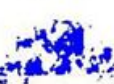

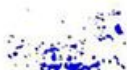

$-4$

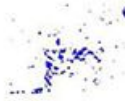

$\left(e_{1}{ }^{2 *}\right)$
$-3$

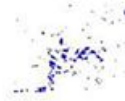

$\left(f_{1}{ }^{2 *}\right)$

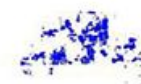

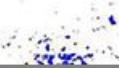

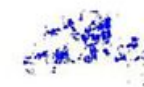

$\sin$
-

$\left(\mathrm{g}_{1}{ }^{2 \%}\right)$

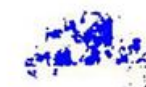

$+4$

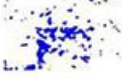

$-3$

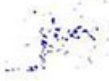

$\left(\mathrm{h}_{1}{ }^{3 *}\right)$

-4t -

$\therefore$ $x+5$

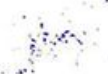

$\left(i_{1}{ }^{3 *}\right)$ ?

$\left(\mathrm{j}_{1}{ }^{3 \%}\right)$
$=13+5$

tives

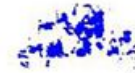

$\therefore$

Figure 4

Comparison of Water Extraction Based on Four Classifiers and Their Different Neighborhood Rule Hotspot Analysis 


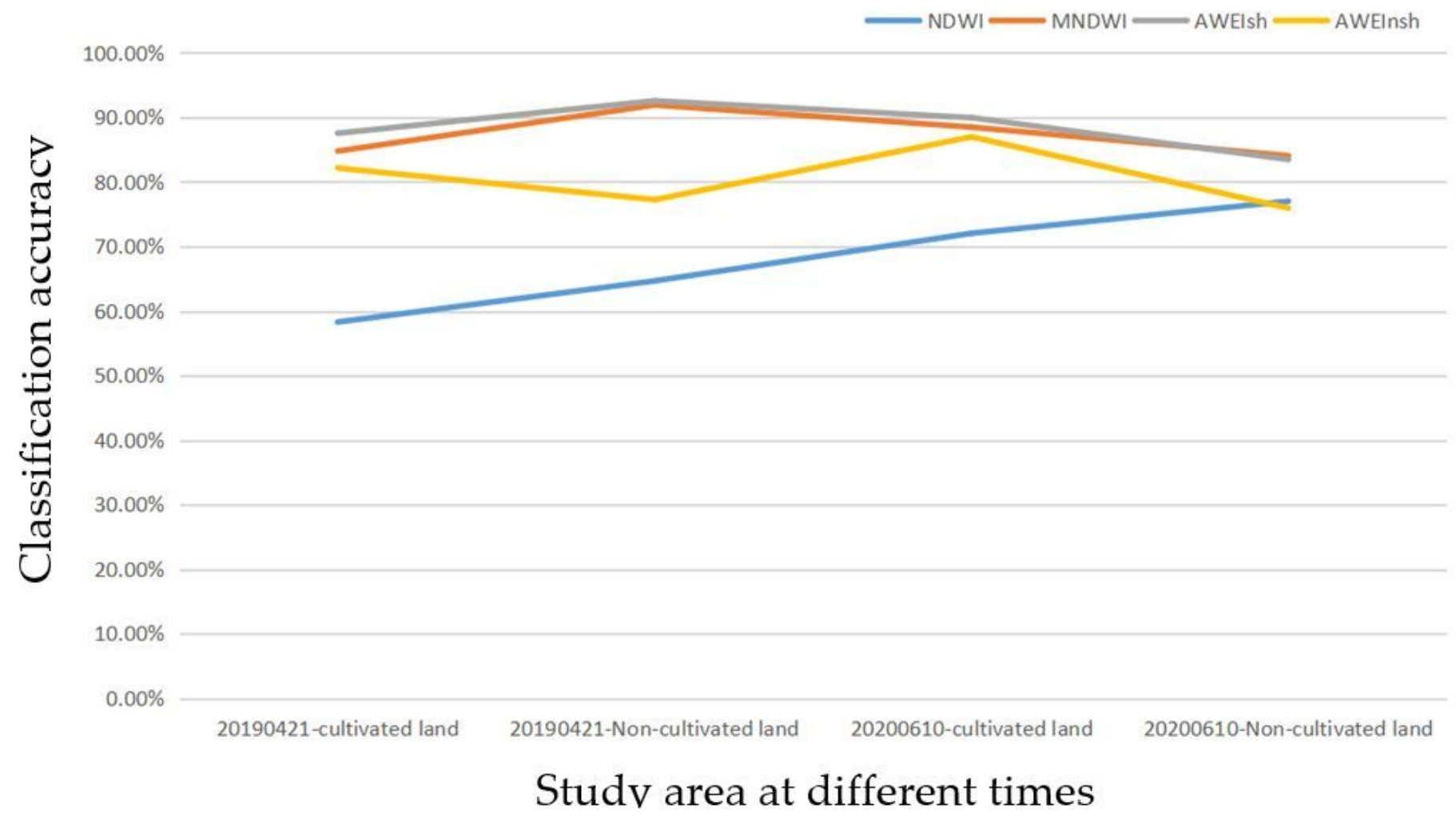

Figure 5

Line chart of classification accuracy of non-cultivated and cultivated water in different periods 